\title{
Breathing life into climate change adaptation
}

Frank Stadler, Luke Houghton

Address correspondence to: Frank Stadler, Department of International Business and Asian Studies, Griffith Business School, Griffith University, Gold Coast Qld 4222, Australia, f.stadler@griffith.edu.au.

\section{Key words}

Biological adaptation

Biologically inspired design

Climate change adaptation

Evolution

Industrial ecology

\section{Abstract/Summary}

The exploration of evolutionary biology and biological adaptation can inform society's adaptation to climate change, particularly the mechanisms that bring about adaptability, such as phenotypic plasticity, epigenetics, and horizontal gene transfer. Learning from unplanned and autonomous biological adaptation may be considered undesirable and incompatible with human endeavour. However, it is argued that there is no need for agency, and planned adaptation is not necessarily preferable over autonomous adaptation. What matters is the efficacy of adaptive mechanisms and their capacity to increase societal resilience to current and future impacts. In addition, there is great scope for industrial ecology to contribute approaches to climate change adaptation that generate system models and system baseline data to inform decision 
making. The problem of 'uncertainty' was chosen as an example of a challenge that is shared by biological systems, IE, and climate change adaptation, to show how biological adaptation might contribute solutions. Finally, the Coastal Climate Adaptation Decision Support tool was used to demonstrate how IE and biological adaptation approaches may be mainstreamed in climate change adaptation planning and practice. In conclusion, there is close conceptual alignment between evolutionary biology and industrial ecology. The integration of biological adaptation thinking can enrich industrial ecology, add invaluable new perspectives to climate change adaptation science, and support industrial ecology's engagement with climate change adaptation. While there should be no major obstacles regarding the collaboration of industrial ecologists with the climate change adaptation community, it is still early days for the mainstreaming of biological adaptation solutions because this depends greatly on successful knowledge transfer and the engagement of open-minded and informed adaptation stakeholders. The next step would be to develop the conceptual underpinnings and methodologies for knowledge transfer from biological adaptation, followed by proof-of-concept studies.

$<$ heading level $1>$ Introduction

The Intergovernmental Panel on Climate Change (IPCC, 2014) suggested that climate change will lead to a reduction in available water resources in dry sub-tropical regions, rising sea levels will increasingly lead to submergence, coastal flooding and coastal erosion, and food security will be significantly undermined. Climate change will make existing health problems worse, especially in developing countries. The IPCC is also concerned that climate change impacts on human societies will lead to deteriorating political security, displacement of people and violent conflict. Urban areas have been 
singled out as particularly vulnerable with a high risk of climate change impacts in the form of extreme meteorological events and consequent heat stress, flooding, landslides, air pollution, drought, and water scarcity. The projections for ecological systems and biodiversity are generally alarming with high risks of wide-spread species extinctions and irreversible regional-scale ecological change (IPCC, 2014).

Society has two broad approaches to deal with climate change. It can avoid climate change or reduce its magnitude, which is the domain of climate change mitigation. Alternatively, society can adjust to the impacts of climate change, which is the domain of climate change adaptation. The IPCC defines climate change adaptation as "the process of adjustment to actual or expected climate and its effects. In human systems, adaptation seeks to moderate or avoid harm or exploit beneficial opportunities" (IPCC, 2014, 5).

For this special issue, the Journal of Industrial Ecology called for contributions that explore and demonstrate how industrial ecology (IE) can support societal adaptation to climate change impacts and make societal systems more resilient. The emphasis is on the unique skillset of the IE community and on examples that directly apply IE concepts, tools, and findings to climate change adaptation research and practice. Industrial ecology is founded on the realisation that the greater societal system, and in particular industrial systems, mirror ecological systems (Frosch, 1992). Central to this philosophy is the idea that there is continuous cycling and utilisation of energy and materials in natural systems and that these are analogues for societal systems, their processes and flows of resources.

This paper discusses the role IE can play in climate change adaptation and makes the case that industrial ecologists should also consider knowledge from evolutionary biology and biological adaptation in addition to ecology. It is argued that 
this expanded view of IE is particularly promising for IE's engagement with climate change adaptation. Knowledge to emerge from exploration of biological adaptation (the evolutionary processes that allow organisms to adjust to their environment, cope with change and thereby enhance their chance of survival) falls into two categories: (1) enablers and facilitators of biological adaptation, and (2) already manifest adaptations, i.e. the physical products of adaptive processes. In the case of enablers and facilitators of biological adaptation, there is now good evidence that, beyond natural selection, there are far more mechanisms at play that contribute to adaptive success in nature, e.g. phenotypic plasticity and epigenetics (Wang, Liu, \& Sun, 2017; Wund, 2012), diversity generators other than recombination (Calo, Billmyre, \& Heitman, 2013), and horizontal gene transfer (Boto, 2010). In other words, there are on one hand adaptation mechanisms that regulate biological adaptation, and on the other hand, there are the resultant physical or behavioural manifestations of such adaptation mechanisms. As for physically or behaviourally expressed adaptations, they are already the focus of biomimeticists who seek to adopt biological inventions for human use (Bhushan, 2009). No doubt much can be learned from biomimetics but it must be stressed that biologically inspired design is, not exclusively but predominantly, concerned with the study of phenotypic biological phenomena such as biomaterials, bio-chemicals, morphological structures and behaviours (Bar-Cohen, 2011). In contrast, climate change adaptation is likely to benefit from the transfer of mechanisms that enable and facilitate biological adaptation. Although both can instruct IE, we believe that enablers and facilitators of biological adaptation are the most promising source of knowledge for societal climate change adaptation. Integration of biological adaptation mechanisms into societal systems will assist managers to create systems with autonomous response capacity and adaptability that is not reliant on 
anticipatory short- or long-term planning. This is not a rejection of planning in climate change adaptation, rather it suggests that the nature of planning should change. In other words, planning should consider how best to integrate and implement biological adaptation mechanisms into societal systems so that the systems become autonomously adaptable and able to respond to an unpredictable spectrum of change. Implementation of solutions inspired by evolutionary processes and mechanisms are unlikely to completely replace planned anticipatory adaptation but rather complement and add to the existing adaptation tool set.

It is also important to note that it would be counterproductive to limit investigation of adaptation solutions to only those that help organisms adapt to climate change. Although there are similarities between natural and societal systems, the impact of climate change on an organism's physiology and ecology is likely to be qualitatively different to climate change impacts on societal systems. Moreover, focusing on adaptation to climate change alone would be unhelpfully limiting when there are also lessons to be learned from biological adaptation to other types of change or ecological pressures. The exception would be adaptation to impacts of climate change on plants and animals that humans depend on for food, fibre and other uses. Because they are organisms themselves and not higher-level socio-technological systems, the management of these resources will benefit from a thorough understanding of how organisms adapt specifically to climate change (Lamke \& Baurle, 2017).

With this in mind, we first discuss IE and its relevance to climate change adaptation. Next, we explain the natural alignment between IE and biological adaptation thinking, and the contribution biological adaptation can make to IE. We then use the problem of uncertainty to demonstrate with examples how biological 
adaptation thinking can add value to both IE and climate change adaptation. Finally, we consider how IE and biological adaptation approaches may be mainstreamed in climate change adaptation practice.

\section{<heading level 1> IE and climate change adaptation}

Industrial ecology is well suited to the investigation of climate change mitigation problem settings but has not yet engaged to any meaningful extent with climate change adaptation. This current situation is somewhat surprising because there is good reason to believe that the IE approach can contribute to climate change vulnerability assessments, adaptation planning and the monitoring and evaluation of adaptation interventions. For example, there are a number of sub-disciplines in IE that formed around key tools that may prove to be especially useful to societal climate vulnerability assessment and adaptation monitoring, namely life cycle analysis (LCA), material flow analysis (MFA), input-output tables (IOT), design for environment, and urban and socio-economic metabolism (Graedel \& Lifset, 2015).

What this contribution might look like can be gauged from examples of recent IE studies that have a strong climate change focus. Particularly pervasive and yet difficult to model impacts of climate change are those on freshwater resources (Hagemann et al., 2013). For instance, in Spain climate change will result in a general decrease of water resources and the need for demand management (Estrela, PérezMartin, \& Vargas, 2012). Against this backdrop of diminishing water resources, it is critical for municipalities to understand their water consumption patterns across sectors in order to plan adaptation measures. Cazcarro and colleagues (2016) used input-output models and geographic information system data to provide micro-scale water footprint analyses to municipal resource managers. Once adaptation measures 
to save water have been identified, it is helpful to understand how effective they might be. Berhanu and colleagues (2017) explored the feasibility of water efficiency and reuse technologies for residential water use by modelling technology adoption cost and performance for varying reuse technologies as well as construction versus retrofit scenarios. This ability to model the impact of various interventions across sectors could provide invaluable decision support in the planning of climate change adaptation measures.

Water availability and its quality is also a major determinant for human health and well-being. Saravanan and colleagues (Saravanan, Mavalankar, Kulkarni, Nussbaum, \& Weigelt, 2015) turned to interdisciplinary methodology including urban metabolism to examine water issues and their relationship to health in urban India. Likewise, climate change will affect the well-being of workers and reduce productivity, for example through higher ambient temperatures and more frequent and severe heatwaves (Kjellstrom, 2016). Scanlon and colleagues (Scanlon, Lloyd, Gray, Francis, \& LaPuma, 2015) showed that LCA can assist in exploring the relationship between industry output and worker health in the municipal solid waste landfill and incineration sector. This proof-of-concept study strongly suggested that product and sectorspecific LCAs could be expanded to also examine and model the climate related health burden on the workforce, and therefore provide adaptation decision and monitoring support to improve occupational health and safety in a warming world.

IE can also contribute to climate change adaptation of the built environment including the housing stock. The built environment is highly vulnerable to climate change impacts, which means that improvements to housing stock and infrastructure must meet adaptation needs (Wilby, 2007). So far IE studies of climate mediated problem settings have been preoccupied with mitigation. For example, Pauliuk and 
colleagues (2013) combined MFA and LCA to model the emissions reduction potential of energy efficiency improvements to the residential building stock. Likewise, Cubi and colleagues (2016) studied the life cycle of white roofs, green roofs, and roof-mounted photo-voltaic panels in terms of their environmental performance. White and green roofs are also under investigation for their potential to reduce heat stress in urban environments due to the urban heat island effect (Larsen, 2015; Razzaghmanesh, Beecham, \& Salemi, 2016). These examples illustrate the capacity of IE approaches to generate system models and baseline data to inform climate change adaptation decision making. In addition, mitigation and adaptation interventions often affect each other, and activities in either domain seldom go without sectoral and cross-sectoral consequences (Harrison, Dunford, Holman, \& Rounsevell, 2016; Landauer, Juhola, \& Söderholm, 2015). It appears that these interactions would become more transparent if they were to be studied in an integrative fashion that includes IE methodologies.

\section{<heading level 1> IE and biological adaptation}

A number of definitions have been put forward for IE (Graedel, Allenby, American, \& Telegraph, 1995), but Frosch $(1992,800)$ paints the most vivid picture of industrial 'organisms' as:

"...being the industrial process or set of industrial processes that leads to a particular product or product family and of the ecology as being the network of all industrial processes as they may interact with each other and live [off] each other, not just in the economic sense but also in the sense of the direct use of each other's material and energy wastes and products." An evolutionary and organism-centric understanding of early IE is also apparent in an introduction to a collection of papers presented at a colloquium titled 'Industrial Ecology' at the National Academy of Science. There, 
Jelinski and colleagues (1992) found that (1) IE is proactive not reactive, meaning that industry itself is the driving force and industrial ecology is not imposed, (2) that IE is designed-in and not added on, thus acknowledging that material flows are determined by how a product and the associated industrial processes are designed, (3) IE is flexible not rigid, expressing the need for industrial processes to be adaptable to changing circumstances, and (4) IE is encompassing and not insular, requiring crosssectoral international and cross-cultural approaches. In hindsight, this characterization of IE lends weight to the view that biological adaptation processes are of central importance to IE. For example, IE being 'designed-in' alludes to the fact that organisms have an intrinsic capacity to evolve and adapt, and that the emergent ecological patterns are the result of organismal interactions that are determined by the organisms' genotypes and phenotypes. Likewise, mention of the 'flexibility' of IE and industrial processes acknowledges the importance of adaptation and adaptive capacity in biological systems. Finally, the boundary spanning property of IE being 'encompassing' not only refers to the fact that IE is interdisciplinary at its core but it also implies that the discipline itself is open to new approaches. One of them should be the engagement with evolutionary biology and biological adaptation in addition to the ecological viewpoint that inspired IE in the first place.

This view is shared by Nikolić (2015) who refers to societal systems as complex adaptive systems that are subject to evolutionary processes facilitated by variation, selection and replication (Holland, 1995). His view of the societal system as mirroring evolutionary processes and the need to integrate evolutionary theory into IE resonates strongly with the central theme of this paper. Nikolic proposed the development of generative models through the study of societal equivalents of evolving complex systems such as individuals and firms and their behaviour, habits, and business 
models. However, he stopped short of advocating a deeper engagement with evolutionary biology and the mechanisms and processes that bring about adaptation in organisms.

<heading level 1> IE, biological adaptation, and climate change adaptation We argue that the integration of biological adaptation thinking into both IE and climate change adaptation research and practice can enrich IE, add invaluable new perspectives to climate change adaptation science, and synergistically support IE's engagement with climate change adaptation. We have chosen the problem of 'uncertainty' as an example of shared challenges and problem settings in biological systems, IE, and climate change adaptation in order to demonstrate with examples how biological adaptation might contribute solutions.

\section{$<$ heading level 2> Uncertainty in IE and climate change adaptation}

The nature of societal and biological systems is highly complex and plagued with uncertainty that obstructs our efforts to better understand these systems. Humans, when faced with uncertainty, invariably try to reduce it in order to gain greater control and industrial ecologists are no exception. For example, manufacturing is dependent on reliable supply streams but considerable uncertainty is introduced to the supply chain when raw materials are sourced from variable waste streams. For example, Linton and colleagues (2002) have shown that the estimation of supply quantities of cathode ray tubes recovered from old televisions is at the mercy of many highly uncertain factors pertaining to consumer behaviour and technological progress, leading to large discrepancies in the forecasting of waste streams. They modelled cathode ray tube waste based on uncertainty values from realistic representative 
distributions and showed that resulting scenarios of available waste volumes varied widely, which makes long-term resource recovery planning extremely difficult.

Schwab and Rechberger (2018) discussed the current state of uncertainty research in MFA and found that there are methods for the treatment of known data uncertainties and that approaches for assessment of uncertainty in MFA range from educated judgement and estimation to attempts of systematic assessment. However, with regard to the latter, they question the merit of quantifying the unquantifiable.

The desire for control and certainty is not unique to IE. Planned and anticipatory climate adaptation practice relies to a large degree on the ability to predict future trends in both climate and society, and therefore ideally on the absence of complexity in societal interactions. However, uncertainty and complexity are ubiquitous in climate and societal systems and difficult to communicate (Cooke, 2015). The Faustian ambitions of complete certainty (knowledge) regarding future climate projections and impacts have led to decision gridlock and delayed adaptation action (Wise et al., 2014). In reality, our knowledge regarding the future states of local climate and its impacts will always be incomplete and uncertain - just as our grasp of industrial and societal systems in IE. Besides, sources of uncertainty are not restricted to climate science and may include uncertainty in demographic, economic and other trends. Consequently, climate change adaptation planning and implementation is riddled with 'wicked' problems to which there are still few practical solutions (e.g. Head, 2014; Moser, Jeffress Williams, \& Boesch, 2012). There is no doubt that elucidation of uncertainties in both climate science and IE is in itself valuable and can inform decision making. Nevertheless, in the face of intangible and often irreducible uncertainty the question arises what can be done to overcome the limitations of uncertainty? Robust decision-making approaches (Dittrich, Wreford, \& Moran, 2016; Hallegatte, 2009) and 
the pathways approach that permits incremental and transformational adaptation action over time as it is needed (Wise et al., 2014) are steps in the right direction. Interestingly, the pathways approach is highly reminiscent of evolutionary adaptation in nature. In the pathways approach impacts are periodically assessed and required adaptive changes are implemented in order to improve resilience. The evolution of species is marked by long periods of stasis interrupted by rapid (transformational) change (Gould, 2002). However, even during periods of stasis, there is incremental adaptation to changing conditions (Dietl, 2013). The next section explains how insights from biological adaptation may further enhance the adaptive capacity of societal systems in the face of uncertainty.

\section{<heading level 2> Learning from biological adaptation}

Some progress has already been made regarding the transfer of biological adaptation mechanisms to the societal domain. For example, Sagarin and Taylor's (2008) edited book, Natural Security, explored the applicability of biological solutions in the context of societal security. Prescott (2008) contributed a chapter to this volume in which she examined different types of uncertainty, how biological systems cope with such uncertainty and how this might inform society's response to uncertainty. In addition, Sagarin and colleagues $(2010 ; 2012)$ identified lessons from nature that can be applied as a set of practices any organization of any size, public or private, can begin to implement immediately: 1) detect change using decentralized sets of observers; 2) embrace redundant solutions to have a hedge against uncertainty; 3) develop symbiotic partnerships to extend adaptive capacity; and 4) create a culture of learning from success to build a feedback loop toward ever greater adaptive capacity. 
Biological systems from the cellular to the ecosystem level have the capacity to autonomously adapt to unforeseeable and uncertain changes in the environment across a range of time scales, from minutes and days to millions of years. However, the abovementioned insights are largely derived from emergent properties of adaptation mechanisms that bring about adaptability in organisms. This means that they lack explanatory and guiding power as to how these lessons might be implemented in societal adaptation. For this to happen, it is important to first understand how organisms adapt, for example to form symbiotic relationships, and only when these mechanisms are understood can they be transferred and integrated into societal systems. There are a myriad of symbiotic relationships in nature but they do not appear out of thin air. They are rather the outcome of complex adaptations to ongoing interactions between organisms (Li et al., 2018; Moran, 2006).

Of particular interest to both IE and climate change adaptation should be the ability of organisms to adapt to a range of environmental conditions with phenotypic plasticity, whereby a number of adaptation mechanisms can generate plasticity in an organism's physical appearance, physiology or behaviour, without altering the genome (Pigliucci, 2001). This is directly applicable to the discussion of uncertainty because phenotypically plastic organisms can adjust rapidly to changing environmental conditions within a single generation without having to evolve genetically over many generations - provided the experienced challenge is within the coping range.

Returning to the previously discussed example of uncertainty in the supply chain for television cathode ray tubes (Linton et al., 2002), we suggest that biological adaptation strategies can inform such an IE problem setting. It can be argued that a manufacturing firm that depends on a particular raw material can either ensure the 
supply is reliable or that supply fluctuations, such as those resulting from seasonality, are known and foreseeable. If that is not the case, the firm can diversify suppliers to fill supply gaps or it can adjust its production volume and product variety in accordance with available supplies. Industrial ecologists accept the similarity between such an industrial supply chain system and ecological food chains in nature (Frosch, 1992). In nature, phenotypic plasticity allows animals to adapt to variability in food type and quality. For example, Hughes and colleagues (2012) showed experimentally that sea urchins exhibit true phenotypic plasticity in response to a change in the type and physical nature of their food. The sea urchins adjusted their morphology to allow for better resource utilisation. In the context of a firm, this might represent modifications to machinery and factory setup to accommodate different raw materials in production.

In the case of climate change, it would be advantageous for a climate exposed business to be able to respond and adjust quickly to a wide range of direct and indirect impacts without requiring major adjustments to the organisational structure, governance framework or business plan. This requires organisational architectures and processes with in-built latitude and operational flexibility, equivalent to phenotypic plasticity in nature.

In summary, our uncertainty example is illustrative, but by no means exhaustive, of the benefits that may be gained from transferring biological adaptation lessons into IE and climate change adaptation science. This is not to distract from the fact that IE is well placed to provide invaluable methodological approaches to climate change adaptation on its own, as we have explained. However, the adaptive capacity gains from integration of IE or biological adaptation individually are likely to be magnified if they were to be employed in concert. In the next section we suggest how 
contributions of both, IE and biological adaptation, are best integrated into the climate change adaptation cycle.

\section{$<$ heading level 1> Operationalizing IE and biological adaptation learning in societal climate change adaptation}

For society to benefit from IE and biological adaptation mechanisms in climate change adaptation they need to be implemented in real life. It is therefore necessary to demonstrate how this integration might be achieved. The Coastal Climate Adaptation Decision Support tool (C-CADS) was chosen to explore the integration process. It has been developed by the National Climate Change Adaptation Research Facility in Australia (NCCARF, 2017a) and aligns closely with other international adaptation planning approaches that have common or very similar steps (Boulter, 2017).

It might appear a contradiction to integrate unplanned autonomous adaptation strategies into the C-CADS or similar adaptation planning approaches. However, the adoption of biological adaptation strategies is not a tacit autonomous process, but requires planning to coordinate research, knowledge transfer, implementation, and monitoring and evaluation. Moreover, adaptation strategies borrowed from nature are likely to complement rather than replace conventional planned adaptation approaches, thus necessitating integration planning.

The climate change adaptation process according to C-CADS includes six major steps: 1) identify challenges, 2) assess risks and vulnerabilities, 3) identify options, 4) evaluate options and prepare the plan, 5) take action, and 6) monitor and evaluate. Each of these steps comprises tasks that contribute to achieving the objectives of the respective climate change adaptation step. In this section, we discuss 
how IE and biological adaptation approaches would be best integrated into each step and the corresponding activities (Figure 1).

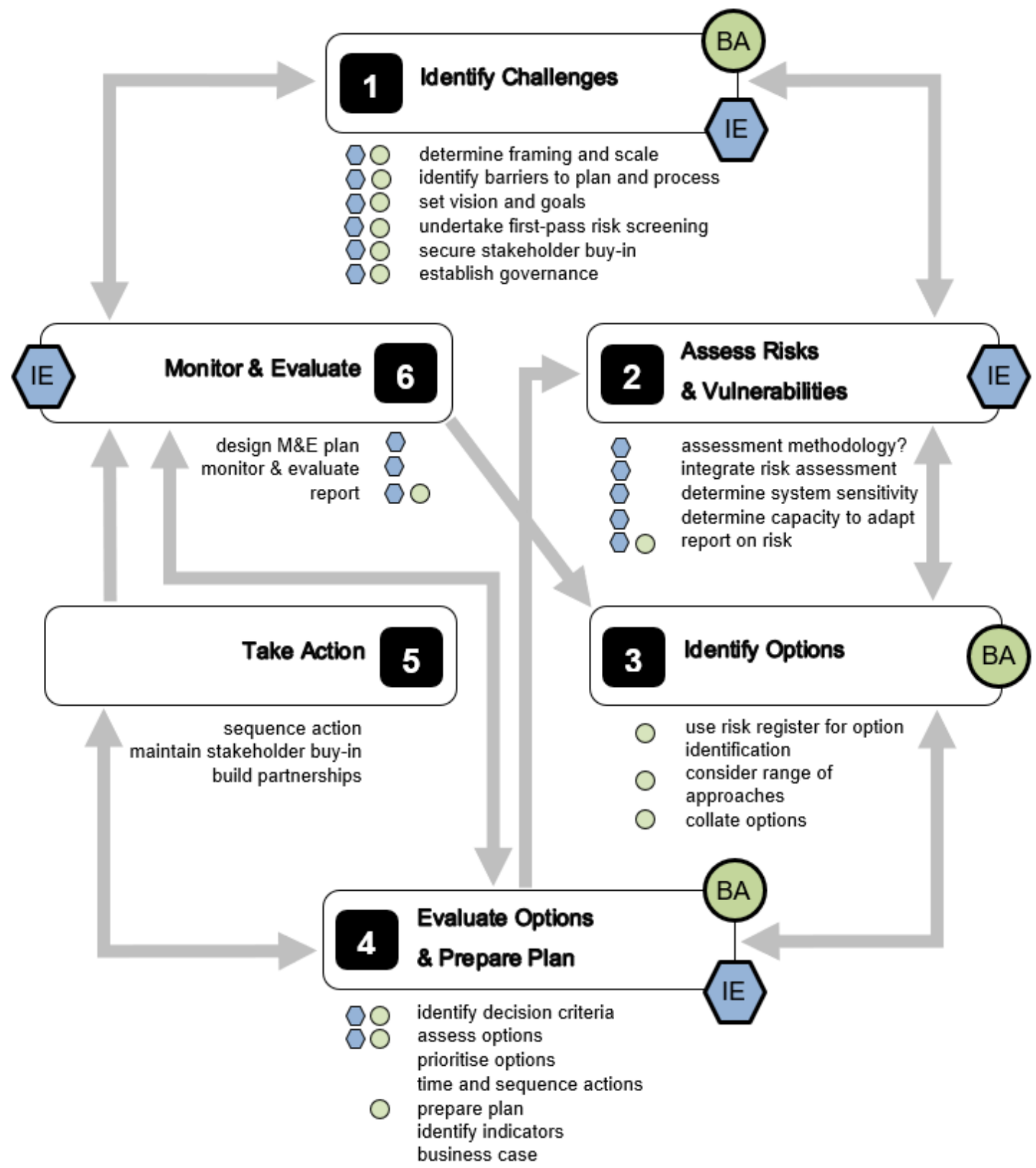

Figure 1: Mapping of IE and biological adaptation learning across the C-CADS adaptation cycle. $B A=$ biological adaptation and IE $=$ industrial ecology. The diagram shows the major steps of the adaptation cycle and the activities for each. Large BA circles and IE hexagons indicate the dominant opportunity for integration of IE and biological adaptation thinking at each step. The small circles and hexagons indicate 
which of the activities would benefit from, or require, IE and biological adaptation input. Grey arrows indicate the adaptation workflow with some workflows providing the option to backtrack and repeat earlier steps if necessary [adopted from the Australian C-CADS tool for coastal climate change adaptation (NCCARF, 2017b)].

Much of the first step in the adaptation cycle (identifying challenges) is setting the scene and preparation for the actual climate change adaptation process. It includes the framing and scoping of the project, the identification of barriers to adaptation, it sets the vision and goal of the adaptation program, it includes a firstpass risk assessment, it garners organisational and stakeholder support, and program governance arrangements are established. We suggest that this first step is critical when it comes to integrating IE and biological adaptation thinking and methodology into the adaptation program. All aforementioned activities need to consider the integration of IE and biological adaptation and its consequences. For example, the CCADS tool recommends a first-pass risk assessment at the outset of the adaptation process. Although this early risk assessment is of limited scope, it may be helpful to already view the adaptation challenge through the prism of IE and biological adaptation. The outcomes of this preliminary risk assessment, and any subsequent indepth risk assessments will need to be communicated effectively to permit the identification of biological adaptation solutions. Feeding biological adaptation knowledge into the climate change adaptation planning process requires interdisciplinary communication. Indeed, the lack of expert facilitators that can traverse with ease the disciplinary boundaries may be a barrier - more so for the implementation of biological adaptation than for IE. Stakeholders will have to be open to these new approaches and there must be sufficient expertise in the project team to 
conduct IE and biological adaptation research and communication activities, particularly with regard to evolutionary knowledge (Snell-Rood, 2016).

The second step along the adaptation journey is the assessment of risks and vulnerabilities. According to the C-CADS tool, this entails decisions regarding the riskassessment methodology to be used, an integrated risk assessment, the determination of the sensitivity of the system to climate change, the identification of the adaptive capacity present, and communication of risks to stakeholders. This step is where IE can make the greatest contribution to climate change adaptation. IE can bring an ecologically holistic view of societal systems to risk assessment, which should lead, in addition to more comprehensive mapping of direct and indirect impacts across the system, also to better quantification of impacts. As discussed earlier with sustainable roof solutions and energy efficiency improvement of housing stock (Cubi et al., 2016; Pauliuk et al., 2013), IE can contribute methodologies such as LCA and MFA to establish baseline system performance, which can then be used to model and assess climate change impacts, vulnerability and adaptive capacity.

Risk and vulnerability assessment per se are activities that do not need to be tailored to facilitate the identification of relevant biological adaptation knowledge and solutions. What matters, however, is the communication of assessment outcomes. It is important for biological adaptation experts (evolutionary biologists) to understand the nature of climate risks and their impacts on societal systems so that they can identify fitting solutions. This emphasises again the importance of the knowledge translation process required for successful interdisciplinary cooperation between the climate adaptation community, industrial ecologists and evolutionary biologists.

The third step in the adaptation cycle is concerned with finding climate change adaptation options. The identification of potential solutions from the vast biological 
adaptation knowledge pool is not a trivial undertaking and will require intimate knowledge of the biological sciences and in particular of evolutionary biology, genetics and ecology (Snell-Rood, 2016). Learning from biological adaptation is a new idea in the context of climate change adaptation but the exploration of biological phenomena for societal benefit in engineering and material sciences, referred to as biomimetics or biologically inspired design, is well established (Bhushan, 2009). In biomimetics, there is particular interest in understanding the process of idea transfer from the biological to the societal domain and idea generation in response to biological inspiration (e.g. Salgueiredo \& Hatchuel, 2016; Sartori, Pal, \& Chakrabarti, 2010; Wilson, Rosen, Nelson, \& Yen, 2010). Cognisant of the vast body of biological knowledge that has been accumulated in the academic literature, biomimetics researchers are turning to systematic and computational methods to mine this repository for problem-specific solutions (Vandevenne, Verhaegen, Dewulf, \& Duflou, 2016; Vincent, 2009). Whether the search for, and transfer of, biological adaptation mechanisms can be approached with the same methodology remains unclear. It is very likely, though, that the transfer of biological adaptation solutions into the societal problem setting will involve some level of abstraction of both the societal challenge and the biological phenomena under consideration in order to support cross-domain communication (Helms, Vattam, \& Goel, 2009). Once matching biological adaptation options have been identified, their principles need to be interpreted with language and terminology that is shared by the climate change adaptation community prior to evaluation and implementation in adaptation plans.

After adaptation options, including biological adaptation solutions, have been identified they need to be evaluated in Step 4 of the adaptation cycle, which includes the identification of evaluation criteria, the assessment of adaptation options, the 
prioritisation of options and adaptation planning. The process of knowledge transfer from biological adaptation to societal climate change adaptation should result in adaptation options that are indistinguishable from other societal adaptation options in terms of their framing and language. However, in practice it will be necessary for biologists to remain available for refinement or identification of additional adaptation options. If IE methodology has been used for risk assessment then it makes sense to also use IE methodology to evaluate adaptation options. When preparing the adaptation plan in Step 4, it will be necessary to document the genesis of those biological adaptation solutions to ensure that the rationale and underlying data for adaptation decisions are not lost in what may be a multi-decadal process of adaptation implementation (Steps 4 and 5) and monitoring and evaluation (Step 6).

Step 6 of the adaptation cycle is concerned with the monitoring and evaluation of adaptation interventions over time. Here, IE approaches should be helpful because IE is equipped to capture and model the performance of societal systems and processes. Moreover, system data generated during the risk assessment step (Step 2) can serve as baseline information for future monitoring and evaluation.

<heading level 1> Discussion

The purpose of this article is primarily to show how IE and biological adaptation can, by themselves and in synergy, inform climate change adaptation research and practice. To our knowledge, it is the first time that biological adaptation has been proposed as a potential solution space for societal climate change adaptation, even though the two domains share a common challenge, which is to understand what enables individuals, groups and larger systems to adapt to change. It is precisely because of this inescapable similarity that evolutionary biology and its growing 
understanding of adaptation mechanisms must be a source of solutions for societal climate change adaptation. As for IE, it illuminates societal processes on a systemwide scale, and can therefore contribute much to the field of climate change adaptation, such as methods and approaches for risk and vulnerability assessment and monitoring and evaluation. IE as a discipline expresses a deep interest in nature, a view of nature as a model, and a belief that there is merit in learning from nature (Isenmann, 2002). Consequently, engagement with biological adaptation mechanisms as proposed here could be accommodated by IE as a further expansion of previous evolutionary thinking. In particular, incorporation of biological adaptation knowledge and close attention to evolutionary mechanisms that shape organisms and their ecological relationships is bound to strengthen IE's conceptual underpinnings and its approach to climate change adaptation problem settings.

There should be no major obstacles regarding the collaboration of industrial ecologists with the climate change adaptation community, but it is still early days for the mainstreaming of biological adaptation solutions in climate change adaptation. Although we made the case that evolutionary biology and its insights into the workings of biological adaptation can provide valuable lessons and models to societal climate change adaptation, this depends greatly on successful knowledge transfer and the engagement of open-minded and informed adaptation stakeholders. We have laid out the key criteria and considerations for engaging with biological adaptation knowledge, which is marked by many challenges. For example, the biological adaptation mechanisms have to be thoroughly understood within their own domain first, and then they have to be abstracted in order to support transdisciplinary comparison and application. This type of knowledge transfer requires evolutionary and molecular biologists to fruitfully communicate with the IE and climate adaptation community. 
There will be the need for uniquely qualified knowledge brokers to liaise and facilitate this collaboration of disciplines.

Another major barrier could be the lack of agency in biological adaptation. Biological adaptation is largely autonomous, reactive, and unconscious - adaptation happens without the individual organism making conscious adaptation decisions. Therefore, learning from biological adaptation may be considered undesirable and incompatible with human endeavour. However, it is probably counterproductive to assume that agency is required for adaptive capacity and that planned adaptation is preferable over autonomous adaptation. In the end, what matters is the efficacy of adaptive mechanisms and their capacity to increase resilience to current and future impacts. It would be short-sighted to dismiss the vast repertoire of adaptation solutions that enable biological systems to cope with change merely because the adapting systems may not have conscious choice over their destiny and lack any foresight as we understand it.

Much of biological adaptation involves the generation of diversity of one sort or another to produce variants that can cope with the challenges at hand. Applying this approach directly to human society, to the detriment of those individuals (people, firms, organisations) that are less adapted, would be ethically questionable and raise the spectre of Malthusianism and Social Darwinism which must be avoided (Claeys, 2000). However, it should be possible, with careful planning and safety nets in place, to generate and test multiple solutions and minimize negative outcomes for the test population. For example, this could be achieved with a staged process of exploration first with desk-top modelling, followed by experimental verification, and finally pilot studies. Any societal system with a multitude of replicates such as franchises or 
government services may be suitable for such testing of biological adaptation solutions.

\section{$<$ heading level $1>$ Conclusion}

In summary, IE is already well placed to contribute meaningfully to climate adaptation research and practice. However, substantial multidisciplinary research is required to develop the conceptual underpinnings for learning and knowledge transfer from biological adaptation to both IE and climate adaptation, and to conduct proof-ofconcept studies to demonstrate feasibility and efficacy. Moreover, it is unclear whether a sufficiently large pool of investigators exists with the skill set required for, and the interest in, this type of interdisciplinary research. Considerable effort will need to be made to train researchers and educate climate change adaptation stakeholders.

Lessons from nature and the ecological view of human society and its processes may also help to resolve many other problems that elude traditional problem solving and governance, e.g. crime prevention, drug and alcohol policy, international relations, energy policy, climate change mitigation, pollution and much more. We believe the time is right to breathe life into climate change adaptation. Hopefully this article will provide the catalyst for vigorous discussion and collaboration between evolutionists, industrial ecologist and the climate change adaptation community to advance domain-spanning paradigm-traversing adaptation science that explores the wealth of ecological and adaptation knowledge manifest in nature.

\section{$<$ heading level 1> Acknowledgements}

We thank our reviewers who have made many excellent observations and suggestions, some of which enriched the discussion, and others that could not be 
addressed even though they would greatly advance thinking at the nexus between IE, biological adaptation and climate change adaptation. This is because the aim was, in the first instance, a concise and accessible treatment of how IE and biological adaptation can contribute to climate adaptation research and practice. Early reviews by $\mathrm{Dr}$ Gregory P. Dietl from the Department of Earth and Atmospheric Sciences, Cornell University, Ithaca, NY, greatly improved the manuscript. 
$<$ heading level 1> References

Bar-Cohen, Y. (2011). Biomimetics : Nature-Based Innovation: CRC Press.

Berhanu, B. M., Blackhurst, M., Kirisits, M. J., Jamarillo, P., \& Carlson, D. (2017). Feasibility of Water Efficiency and Reuse Technologies as Demand-Side Strategies for Urban Water Management. Journal of Industrial Ecology, 21(2), 320-331. doi:10.1111/jiec.12430

Bhushan, B. (2009). Biomimetics: lessons from nature--an overview. Philosophical transactions. Series A, Mathematical, physical, and engineering sciences, 367(1893), 1445-1486. doi:10.1098/rsta.2009.0011

Boto, L. (2010). Horizontal Gene Transfer in Evolution: Facts and Challenges. Proceedings: Biological Sciences, 277(1683), 819-827. doi:10.1098/rspb.2009.1679

Boulter, S. (2017). Building the knowledge base for adaptation action. CoastAdapt Information Manual 1, 2nd edn. Gold Coast: National Climate Change Adaptation Research Facility.

Calo, S., Billmyre, R. B., \& Heitman, J. (2013). Generators of phenotypic diversity in the evolution of pathogenic microorganisms. PLoS pathogens, 9(3), e1003181. doi:10.1371/journal.ppat.1003181

Cazcarro, I., Duarte, R., \& Sánchez Chóliz, J. (2016). Tracking Water Footprints at the Micro and Meso Scale: An Application to Spanish Tourism by Regions and Municipalities. Journal of Industrial Ecology, 20(3), 446-461. doi:10.1111/jiec.12414

Claeys, G. (2000). The "Survival of the Fittest" and the Origins of Social Darwinism. Journal of the History of Ideas, 61(2), 223-240.

Cooke, R. M. (2015). Messaging climate change uncertainty. Nature Clim. Change, 5(1), 810. doi:10.1038/nclimate2466

http://www.nature.com/nclimate/journal/v5/n1/abs/nclimate2466.html\#supplementaryinformation 
Cubi, E., Zibin, N. F., Thompson, S. J., \& Bergerson, J. (2016). Sustainability of Rooftop Technologies in Cold Climates: Comparative Life Cycle Assessment of White Roofs, Green Roofs, and Photovoltaic Panels. Journal of Industrial Ecology, 20(2), 249-262. doi:10.1111/jiec.12269

Dietl, G. P. (2013). The great opportunity to view stasis with an ecological lens. Palaeontology, 56(6), 1239-1245. doi:10.1111/pala.12059

Dittrich, R., Wreford, A., \& Moran, D. (2016). A survey of decision-making approaches for climate change adaptation: Are robust methods the way forward? Ecological Economics, 122, 79-89. doi:10.1016/j.ecolecon.2015.12.006

Estrela, T., Pérez-Martin, M. A., \& Vargas, E. (2012). Impacts of climate change on water resources in Spain. Hydrological Sciences Journal, 57(6), 1154-1167. doi:10.1080/02626667.2012.702213

Frosch, R. A. (1992). Industrial Ecology: A Philosophical Introdution. Proceedings of the National Academy of Sciences of the United States of America, 89(3), 800.

Gould, S. J. (2002). The structure of evolutionary theory. Cambridge, Mass;London;: Belknap Press of Harvard University Press.

Graedel, T. E., Allenby, B. R., American, T., \& Telegraph, C. (1995). Industrial ecology. Englewood Cliffs, N.J U6 - ctx_ver=Z39.882004\&ctx_enc=info\%3Aofi\%2Fenc\%3AUTF8\&rfr_id=info\%3Asid\%2Fsummon.serialssolutions.com\&rft_val_fmt=info\%3Aofi\%2Ff $\mathrm{mt} \% 3 A k e v \% 3 \mathrm{Amtx} \% 3 \mathrm{Abook \& rft.genre=book \& rft.title=Industrial+ecology \& rft.au=Grae}$ del\%2C+T.+E\&rft.au=Allenby\%2C+Braden+R\&rft.date=1995-0101\&rft.pub=Prentice+Hall\&rft.externalDocID=b13469344\&paramdict=en-US U7 Book: Prentice Hall.

Graedel, T. E., \& Lifset, R. J. (2015). Industrial ecology's first decade. In.

Hagemann, S., Chen, C., Clark, D. B., Folwell, S., Gosling, S., Haddeland, I., . . Ludwig, F. (2013). Climate change impact on available water resources obtained using multiple 
global climate and hydrology models. Earth System dynamics, 4(1), 129-144. doi:10.5194/esd-4-129-2013

Hallegatte, S. (2009). Strategies to adapt to an uncertain climate change. Global environmental change, 19(2), 240-247. doi:http://dx.doi.org/10.1016/j.gloenvcha.2008.12.003

Harrison, P. A., Dunford, R. W., Holman, I. P., \& Rounsevell, M. D. A. (2016). Climate change impact modelling needs to include cross-sectoral interactions. Nature Climate Change, 6(9), 885-890. doi:10.1038/nclimate3039

Head, B. W. (2014). Evidence, Uncertainty, and Wicked Problems in Climate Change Decision Making in Australia. Environment and Planning C: Government and Policy, 32(4), 663-679. doi:10.1068/c1240

Helms, M., Vattam, S. S., \& Goel, A. K. (2009). Biologically inspired design: process and products. Design Studies, 30(5), 606-622. doi:10.1016/j.destud.2009.04.003

Holland, J. H. (1995). Hidden Order. How Adaptation Builds Complexity: Addison-Wesley Publishing Company, Inc.

Hughes, A. D., Brunner, L., Cook, E. J., Kelly, M. S., \& Wilson, B. (2012). Echinoderms display morphological and behavioural phenotypic plasticity in response to their trophic environment. PLoS One, 7(8), e41243. doi:10.1371/journal.pone.0041243

IPCC. (2014). Climate Change 2014: Impacts, Adaptation, and Vulnerability. Part B: Regional Aspects. Contribution of Working Group II to the Fifth Assessment Report of the Intergovernmental Panel on Climate Change. Cambridge, Inited Kingdom and New York, NY, USA: Cambridge University Press.

Isenmann, R. (2002). Further Efforts to Clarify Industrial Ecology's Hidden Philosophy of Nature. Journal of Industrial Ecology, 6(3-4), 27-48.

doi:10.1162/108819802766269520

Jelinski, L. W., Graedel, T. E., Laudise, R. A., McCall, D. W., \& Patel, C. K. N. (1992). Industrial Ecology: Concepts and Approaches. Proceedings of the National Academy 
of Sciences of the United States of America, 89(3), 793-797.

doi:10.1073/pnas.89.3.793

Kjellstrom, T. (2016). Impact of Climate Conditions on Occupational Health and Related Economic Losses: A New Feature of Global and Urban Health in the Context of Climate Change. Asia Pacific Journal of Public Health, 28(2_suppl), 28S-37S. doi:10.1177/1010539514568711

Lamke, J., \& Baurle, I. (2017). Epigenetic and chromatin-based mechanisms in environmental stress adaptation and stress memory in plants. Genome biology, 18(1), 124. doi:10.1186/s13059-017-1263-6

Landauer, M., Juhola, S., \& Söderholm, M. (2015). Inter-relationships between adaptation and mitigation: a systematic literature review. Climatic change, 131(4), 505-517. doi:10.1007/s10584-015-1395-1

Larsen, L. (2015). INNOVATIONS IN THE FACE OF CLIMATE CHANGE: Urban climate and adaptation strategies. Frontiers in Ecology and the Environment, 13(9), 486-492.

Li, H., Sosa-Calvo, J., Horn, H. A., Pupo, M. T., Clardy, J., Rabeling, C., . . Currie, C. R. (2018). Convergent evolution of complex structures for ant-bacterial defensive symbiosis in fungus-farming ants. Proceedings of the National Academy of Sciences of the United States of America, 115(42), 10720-10725. doi:10.1073/pnas.1809332115

Linton, J. D., Yeomans, J. S., \& Yoogalingam, R. (2002). Supply Planning for Industrial Ecology and Remanufacturing under Uncertainty: A Numerical Study of LeadedWaste Recovery from Television Disposal. The Journal of the Operational Research Society, 53(11), 1185-1196. doi:10.1057/palgrave.jors.2601418

Moran, N. A. (2006). Symbiosis. Current Biology, 16(20), R866-R871. doi:10.1016/j.cub.2006.09.019

Moser, S. C., Jeffress Williams, S., \& Boesch, D. F. (2012). Wicked Challenges at Land's End: Managing Coastal Vulnerability Under Climate Change. Annual Review of 
Environment and Resources, 37(1), 51-78. doi:10.1146/annurev-environ-021611135158

NCCARF. (2017a). The adaptation process. Coastal Climate Adaptation Decision Support (C-CADS). Retrieved from https://coastadapt.com.au/coastal-climate-adaptationdecision-support-c-cads

NCCARF. (2017b). The adaptation process. Coastal Climate Adaptation Decision Support (C-CADS). Retrieved from https://coastadapt.com.au/coastal-climate-adaptationdecision-support-c-cads

Nikolić, I. (2015). IE = Industrial Evolution? Journal of Industrial Ecology, 19(2), 198-200. doi:10.1111/jiec.12246

Pauliuk, S., Sjöstrand, K., \& Müller, D. B. (2013). Transforming the Norwegian dwelling stock to reach the 2 degrees celsius climate target: Combining material flow analysis and life cycle assessment techniques. Journal of Industrial Ecology, 17(4), 542-554. doi:10.1111/j.1530-9290.2012.00571.x

Pigliucci, M. (2001). Phenotypic plasticity: beyond nature and nurture. London;Baltimore, Md;: Johns Hopkins University Press.

Prescott, E. M. (2008). Corporations and Bureaucracies under a Biological Lens. In R. D. Sagarin \& T. Taylor (Eds.), Natural Security : A Darwinian Approach to a Dangerous World. Berkerley, UNITED STATES: University of California Press.

Razzaghmanesh, M., Beecham, S., \& Salemi, T. (2016). The role of green roofs in mitigating Urban Heat Island effects in the metropolitan area of Adelaide, South Australia. Urban Forestry \& Urban Greening, 15, 89-102. doi:10.1016/j.ufug.2015.11.013 Sagarin, R. D., Alcorta, C. S., Atran, S., Blumstein, D. T., Dietl, G. P., Hochberg, M. E., . . Vermeij, G. J. (2010). Decentralize, adapt and cooperate: two years ago Raphael D. Sagarin and colleagues proposed that security systems should learn from nature. Now they've worked with defence professionals on putting that call into practice. Nature, 465(7296), 292. 
Sagarin, R. D., \& Taylor, T. (2008). Natural Security : A Darwinian Approach to a Dangerous World. Berkerley, UNITED STATES: University of California Press.

Sagarin, R. D., \& Taylor, T. (2012). Natural security: how biological systems use information to adapt in an unpredictable world. Security Informatics, 1(1), 1-9. doi:10.1186/2190$8532-1-14$

Salgueiredo, C. F., \& Hatchuel, A. (2016). Beyond analogy: A model of bioinspiration for creative design. Artificial Intelligence for Engineering Design, Analysis and Manufacturing : Al EDAM, 30(2), 159. doi:10.1017/S0890060416000044

Saravanan, V. S., Mavalankar, D., Kulkarni, S. P., Nussbaum, S., \& Weigelt, M. (2015). Metabolized-Water Breeding Diseases in Urban India: Sociospatiality of Water Problems and Health Burden in Ahmedabad City. Journal of Industrial Ecology, 19(1), 93-103. doi:10.1111/jiec.12172

Sartori, J., Pal, U., \& Chakrabarti, A. (2010). A methodology for supporting "transfer" in biomimetic design. Al EDAM, 24(4), 483-506. doi:10.1017/S0890060410000351

Scanlon, K. A., Lloyd, S. M., Gray, G. M., Francis, R. A., \& LaPuma, P. (2015). An Approach to Integrating Occupational Safety and Health into Life Cycle Assessment: Development and Application of Work Environment Characterization Factors. Journal of Industrial Ecology, 19(1), 27-37. doi:10.1111/jiec.12146

Schwab, O., \& Rechberger, H. (2018). Information Content, Complexity, and Uncertainty in Material Flow Analysis. Journal of Industrial Ecology, 22(2), 263-274. doi:10.1111/jiec.12572

Snell-Rood, E. (2016). Interdisciplinarity: Bring biologists into biomimetics. Nature, 529(7586), 277-278. doi:10.1038/529277a

Vandevenne, D., Verhaegen, P.-A., Dewulf, S., \& Duflou, J. R. (2016). SEABIRD: Scalable search for systematic biologically inspired design. Artificial Intelligence for Engineering Design, Analysis and Manufacturing : AI EDAM, 30(1), 78-95. doi:10.1017/S0890060415000177 
Vincent, J. F. V. (2009). Biomimetics--a review. Proceedings of the Institution of Mechanical Engineers.Part $H$, Journal of engineering in medicine, 223(8), 919-939. doi:10.1243/09544119JEIM561

Wang, Y., Liu, H., \& Sun, Z. (2017). Lamarck rises from his grave: parental environmentinduced epigenetic inheritance in model organisms and humans. Biological Reviews, 92(4), 2084-2111. doi:10.1111/brv.12322

Wilby, R. L. (2007). A Review of Climate Change Impacts on the Built Environment. Built Environment (1978-), 33(1), 31-45. doi:10.2148/benv.33.1.31

Wilson, J. O., Rosen, D., Nelson, B. A., \& Yen, J. (2010). The effects of biological examples in idea generation. Design Studies, 31(2), 169-186. doi:http://dx.doi.org/10.1016/j.destud.2009.10.003

Wise, R. M., Fazey, I., Stafford Smith, M., Park, S. E., Eakin, H. C., Archer Van Garderen, E. R. M., \& Campbell, B. (2014). Reconceptualising adaptation to climate change as part of pathways of change and response. Global environmental change, 28, 325336. doi:http://dx.doi.org/10.1016/i.gloenvcha.2013.12.002

Wund, M. A. (2012). Assessing the impacts of phenotypic plasticity on evolution. Integrative and comparative biology, 52(1), 5-15. doi:10.1093/icb/ics050 
<heading level 1> About the authors

Frank Stadler, PhD, was research coordinator at the Australian National Climate Change Adaptation Research Facility (NCCARF) from 2008 to 2013, where he contributed to national adaptation research planning and coordinated a portfolio of adaptation research projects. As a biologist with a keen interest in evolutionary biology and biologically inspired design, he recognised the parallels between societal and biological systems and the similarities between climate change adaptation and adaptation in nature. He currently holds an adjunct position at the Department of International Business and Asian Studies, Griffith University, which allowed him to develop the ideas presented in this article.

Luke Houghton, $\mathrm{PhD}$, is a Senior Lecturer in the Department of International Business and Asian Studies. Dr Houghton is an expert in the field of Complex Problem Solving in organisations and large social and technical systems. Second to that he has a growing interest in Higher Education research. Luke has been published in the Information Systems Journal, Australasian Journal of Educational Technology and The Journal of Information Technology Education. He also has publications in the Oxford Review of Education, Higher Education Research and Development, Australasian Journal of Information Systems, Emergence: the Journal of Complexity and Organisation, Journal of the Operational Research Society and Systems Research and Behavioural Science. 